\title{
An innovative method to assess and manage residual stresses in additively manufactured titanium
}

\author{
A.Germain ${ }^{\mathrm{a},}$, I.Freiherr von Thüngen ${ }^{\mathrm{b}}$, M.Piellard ${ }^{\mathrm{b}}$, C.Metton $^{\mathrm{a}}$ \\ ${ }^{\mathrm{a} S a f r a n}$ Additive Manufacturing, ${ }^{\mathrm{b}}$ Materials and Processes research group, Safran Tech, Magny-Les-Hameaux, France
}

$\underline{* \text { aurele.germain@safrangroup .com }}$

\begin{abstract}
$\underline{\text { Abstract }}$
A simple method for residual stresses (RS) evaluation in additively manufactured titanium samples is described in this study. This method allows to obtain samples that are separated from the build plate but still include building's RS. Thanks to these samples, the influence of time and temperature on thermal stress relieving performance and microstructural evolution for Ti64 alloy processed by LBM have been analysed. Additionally, the obtained data allowed to compare the thermal stress relief behaviour of additively manufactured parts to conventional wrought alloy. Process simulations have also been undertaken to predict RS fields and check this method accuracy.
\end{abstract}

\section{Introduction}

Metallic additive manufacturing, and particularly the Laser Beam Melting (LBM) process is showing more and more potential for serial production of complex and high value parts. Nevertheless, a still remaining obstacle to fully benefit from the process is the management of residual stresses [1].

Most additive manufacturing processes generate high thermal gradients during building [2]. Thereby strong RS are induced. These RS can lead to many problems such as deformations during the whole process or cracks during and after building. This phenomenon is particularly strong with Ti64 [3] as its thermal conductivity and diffusivity are low, which generate high RS [1]. Therefore, a better understanding of RS is mandatory to properly manage additive manufacturing.

Several methods have been developed to asses RS in additive manufactured parts such as the cantilever and the bridge samples [4], [5]. These methods are based on the deformations induced by an incomplete separation from the build plate by Electrical Discharge Machining (EDM). Therefore, deformations can be measured and then used as strain gauges in order to evaluate stresses.

The proposed method to evaluate RS gives the possibility to obtain individual samples free from any substrate. These samples can be used to perform various stress relieving tests from one build plate.

\section{$\underline{\text { Material and experiments }}$}

More than 70 cylinders shaped specimens were built on the same plate with the LBM process on a Renishaw RenAM 500M machine. The used parameters were a layer thickness of $60 \mu \mathrm{m}$, a power of $400 \mathrm{~W}$, a distance between points of $80 \mu \mathrm{m}$ and a hatch of $0,1 \mathrm{~mm}$. The samples were manufactured with a stripe scanning strategy, with a $67^{\circ}$ rotation angle on a Ti64 plate of $250 * 250 * 15 \mathrm{~mm}$, heated at $170^{\circ} \mathrm{C}$. The powder used, was a standard Renishaw powder of Ti64 (Ti-6Al-4V) ELI with a $20 \mu \mathrm{m}$ to $45 \mu \mathrm{m}$ size distribution

The build geometry is a simple vertical cylinder of $12 \mathrm{~mm}$ in diameter and $60 \mathrm{~mm}$ in height as shown in Figure 1. To obtain a deformation by redistributing the RS, the cylinder is slit trough the diameter on a total length of $46 \mathrm{~mm}$. A similar sample has been studied in a recent report [6] with interesting results, that are in agreement with the study presented here. In the present study, a square base is used to make sure that the plate does not interfere with the RS state in the cylindrical part of the sample. Furthermore, it permits an easy clamping of the samples during the EDM cutting and ensures a good repeatability. In order to know the build direction in the machine, labels are implemented on the top surface and help to perform a centred EDM cutting. Finally, a cavity is directly designed at the bottom of the specimen to act as a stopping point for the EDM cutting. This also guarantees a repeatable cutting length. The position of the cavity has been selected to ensure that the RS field above it, is not significantly affected by the separation from the plate. This point will be discussed later with RS simulations.
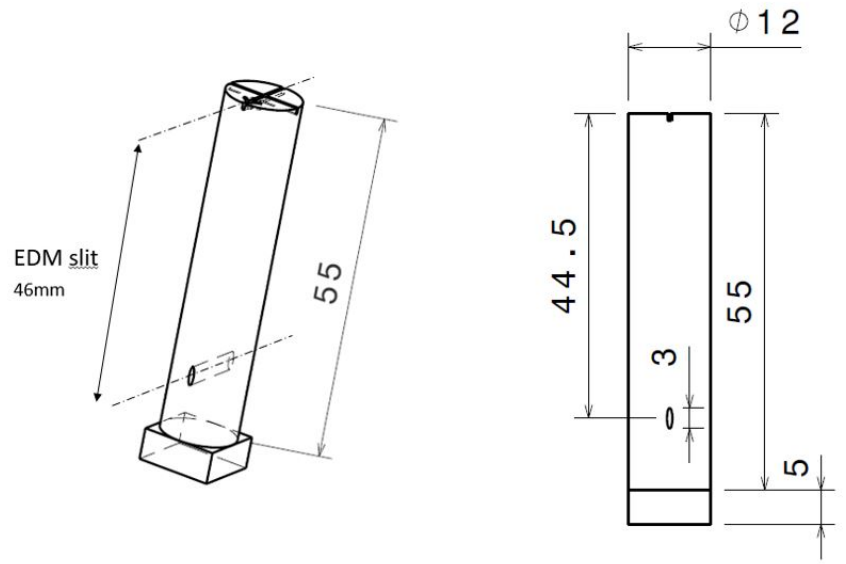

Figure 1 : Schematic detailing the sample geometry and the EDM cutting strategy

Unlike the contour method, which is often used to measure the RS in additive manufacturing [7], [8], the technique used here is based on a simple macro deformation measurement. After the vertical EDM cutting, the sample shows an important deflection, with the two half cylinders diverging from the cutting plane. This deformation can be seen in Figure 2. Compared to a common cantilever sample analysis [9], the design of the sample allows to keep RS after separation from the plate and therefore to easily perform various stress relief tests independently, on a large quantity of samples and to measure the deformation afterwards. 


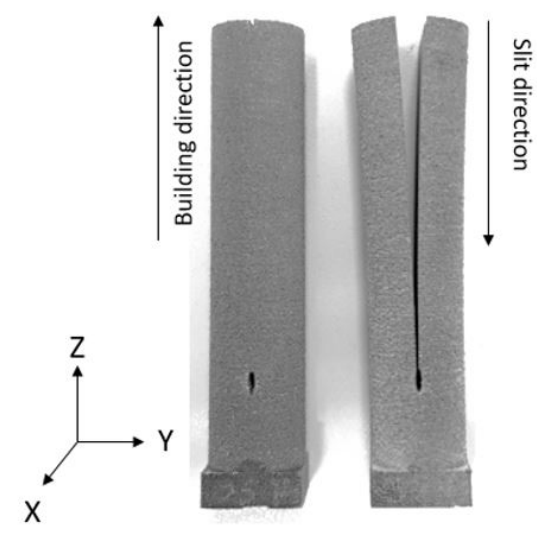

Figure 2: Picture of as-built (left) and slit (right) samples. The deformation is clearly visible after the EDM cutting.

The EDM machine used for this study is a GF AgieCharmilles CUT 20P. The different samples were cut with the same parameters, always in the same direction. A brass wire of $0.1 \mathrm{~mm}$ was used, with a water injection from top to bottom to remove the material produced by the electrical machining.

To measure the sample shape after cutting, a commercial GOM Atos Triple Scan (GOM GmbH, Braunschweig, Germany) was used. This system is based on light interferometry with an accuracy of around $50 \mu \mathrm{m}$.

The furnace used for thermal stress relieving tests is a Nabertherm N 120/85 SHA. The temperature was controlled by an instrumented cylinder sample with a thermocouple inserted at mid-thickness of the sample. The soaking time start was controlled by this thermocouple, ensuring that the temperature of the heat treated samples was homogenous in its entire volume.

Various heat treatments were performed from $260^{\circ} \mathrm{C}$ to $730^{\circ} \mathrm{C}$ with soaking times from 2 hours to 50 hours. Each heat treatment was performed with two samples. These heat treatments can be found in Table 1 .

Table 1 : Heat treatments performed in this study

\begin{tabular}{|l|l|l|l|} 
TEMPERATURE $\left({ }^{\circ} \mathbf{C}\right)$ & TIME $($ HOURS) & HEATING SPEED $\left({ }^{\circ} \mathbf{C} / \mathbf{M I N}\right)$ & COOLING RATE $\left({ }^{\circ} \mathbf{C} / \mathbf{M I N}\right)$ \\
\hline $\mathbf{2 6 0}$ & 2 & 40 & 5 \\
$\mathbf{2 6 0}$ & 50 & 40 & 5 \\
$\mathbf{3 7 0}$ & 2 & 40 & 5 \\
$\mathbf{3 7 0}$ & 10 & 40 & 5 \\
$\mathbf{3 7 0}$ & 50 & 40 & 5 \\
$\mathbf{4 8 0}$ & 2 & 40 & 5 \\
$\mathbf{4 8 0}$ & 10 & 40 & 5 \\
$\mathbf{4 8 0}$ & 50 & 40 & 5 \\
$\mathbf{5 4 0}$ & 2 & 40 & 5 \\
$\mathbf{5 4 0}$ & 10 & 40 & 5 \\
$\mathbf{6 0 0}$ & 2 & 40 & 5 \\
$\mathbf{7 3 0}$ & 2 & 40 & 5 \\
$\mathbf{7 3 0}$ & 2 & 40 & 40 \\
\hline
\end{tabular}

The simulations of LBM building and deflection due to EDM cutting were conducted with the commercial software Simufact Additive v4.0 from MSC Inc. These simulations evaluated the RS after building, after samples removing from the plate and after EDM cutting.

\section{$\underline{\text { Results and discussions }}$}

1. Geometry optimization

With the aim to have a simple yet effective geometry for this study, multiple iterations on the geometry have been performed. With the help of a simulation it was possible to ensure that the RS map was similar before and after separation by the EDM plate removal. Results of the simulation for mid-plane cross-section of the sample in the $Z$ direction are presented in Figure 3. 

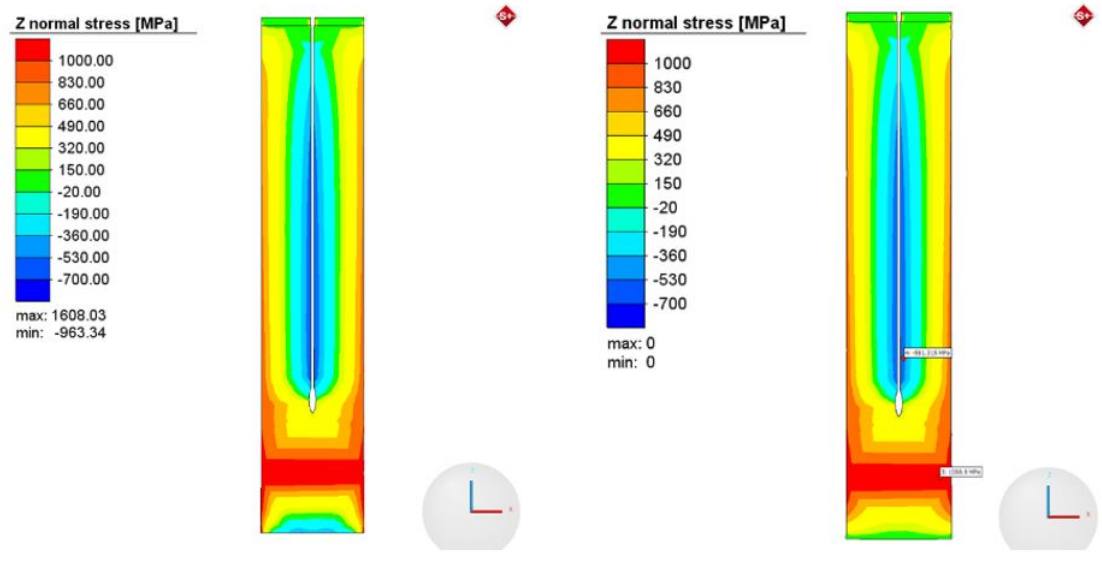

Figure $3:$ On the left, a simulation result of the RS in the $Z$ direction for the samples before separation from the plate. On the right, the same model after separation from the plate.

No significant change is observed in the upper part of the sample. This result shows the sample geometry to be efficient for RS evaluation even after the EDM plate removal.

\section{As-built deformation after EDM cutting}

The deflection values were taken on the outer surface of the sample at different heights. After some tests, the chosen measurement was the maximum distance between the outer surfaces at a distance of $50 \mathrm{~mm}$ from the base of the cylinder, designated as [AB]. The measurement schematic can be seen in Figure 4. This allows having a quick and easy analysis that could be performed in the future with very simple tools as a calliper.

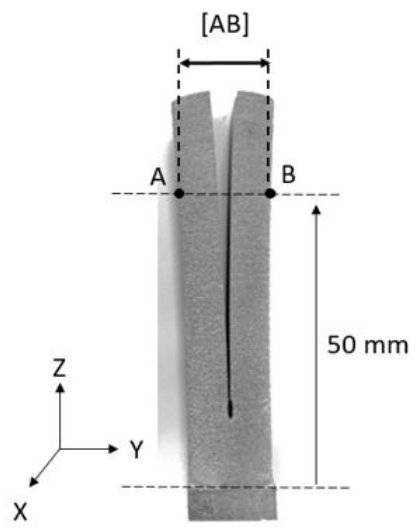

Figure 4: Illustration of the measurement made on the different samples

On an average of five "as-built" samples, the average distance measured between the outer surfaces was $14,60 \mathrm{~mm}$ with a very satisfying standard deviation of $0.09 \mathrm{~mm}$.

\section{Simulations of as-built samples before and after EDM cutting}

The simulations performed with Simufact Additive, presented at the centre plane in Figure 5, show that for the X and Y component, the RS on the upper part of the sample, i.e. above the cavity, is mainly low. For the $\mathrm{X}$ direction the maximum compressive stress is lower than $360 \mathrm{MPa}$, for the $\mathrm{Y}$ direction, the higher compressive stress seems to be lower than $100 \mathrm{MPa}$ and is mostly present in the centre of the cylinder. The tensile stress is lower than $320 \mathrm{MPa}$ in both $\mathrm{X}$ and $\mathrm{Y}$ directions. For the $\mathrm{Z}$ direction that corresponds to the building direction, the centre of the sample is in compression and the surface is in tension.

This important tensile stress in the surface area, will tend to shrink the material. Contrarily, the compressive stress in the centre will tend to extend it during the EDM cutting, which leads to a redistribution of the RS. The two half cylinders will therefore bend away from the centre plane resulting in the deformation observed during the experiment.

The distance $[\mathrm{AB}]$ predicted by Simufact for a slit sample in the as-built state is $14,58 \mathrm{~mm}$, which is very close to the average $14,6 \mathrm{~mm}$ previously measured. 


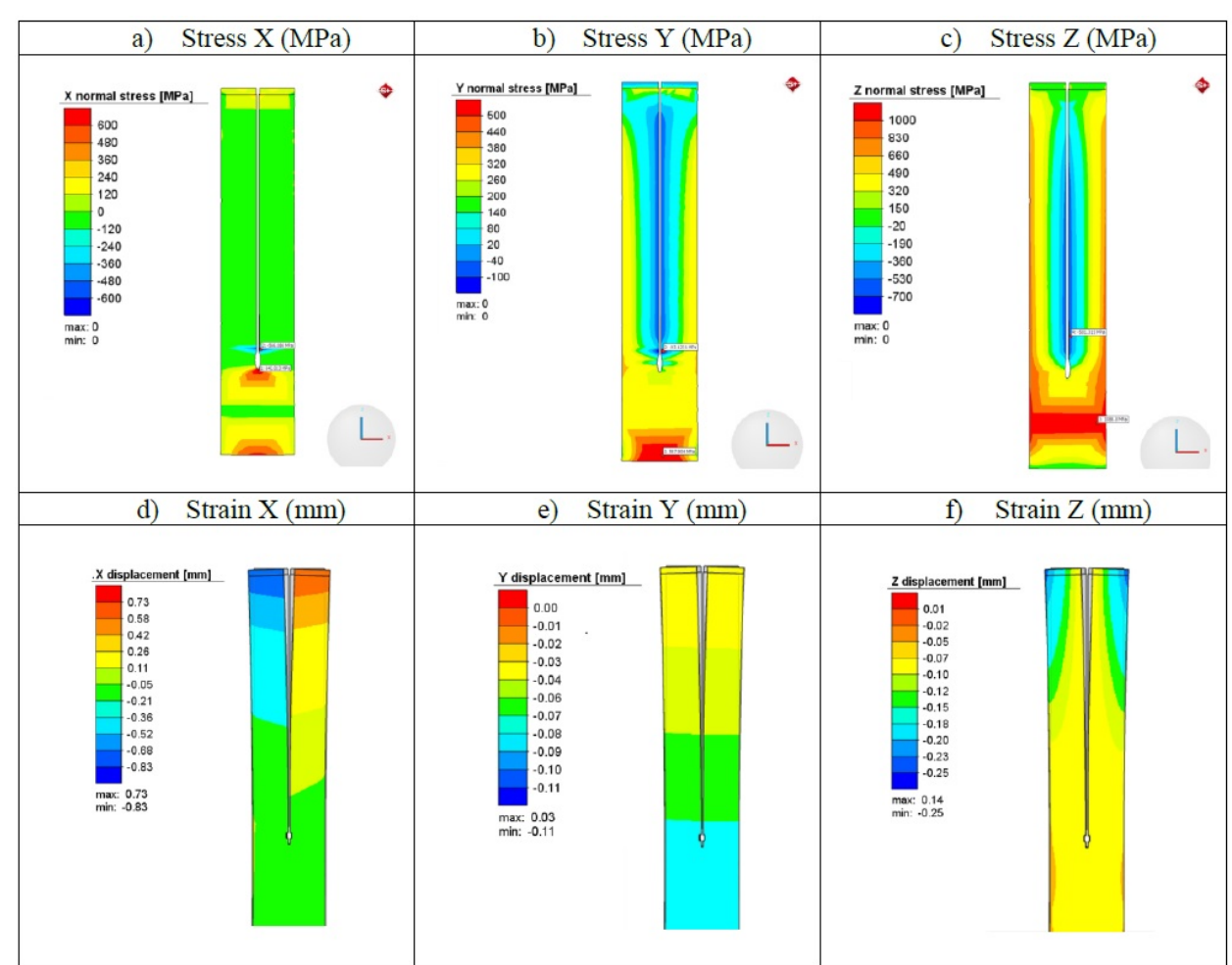

Figure $5: X, Y$ and $Z$ residual stress predicted by Simufact are showed respectively in a, $b, c$. The simulated displacement is visible for the $X, Y, Z$ directions in figure $d, e, f$.

4. Thermal stress relieving

Multiples studies have reported the effect on time and temperature on stress relieving at various temperatures [10]-[12] and have shown that for a conventional Ti64 a temperature of $730^{\circ} \mathrm{C}$ for 2 hours was sufficient to suppress $100 \%$ of the RS. In our knowledge there is no published study that established the effect of various thermal stress relieving treatments on additive manufactured Ti64.

The influence of various thermal stress relieving treatments on the deformation obtained after EDM cutting is illustrated in Figure 6.

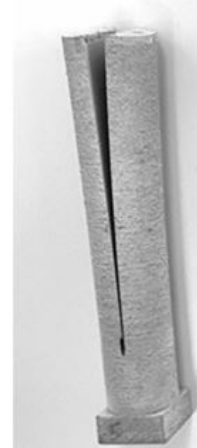

AS BUILT

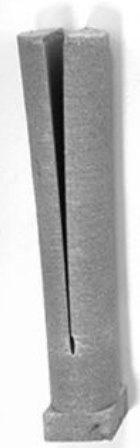

$260^{\circ} \mathrm{C} / 2 \mathrm{H}$

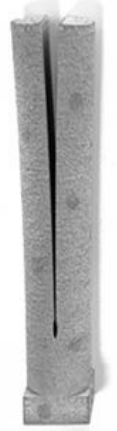

$370^{\circ} \mathrm{C} / 2 \mathrm{H}$

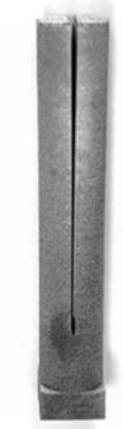

$480^{\circ} \mathrm{C} / 2 \mathrm{H}$

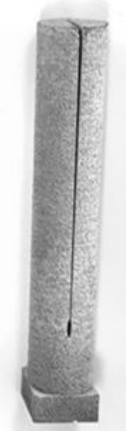

$540^{\circ} \mathrm{C} / 2 \mathrm{H}$

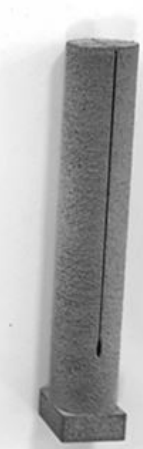

$600^{\circ} \mathrm{C} / 2 \mathrm{H}$

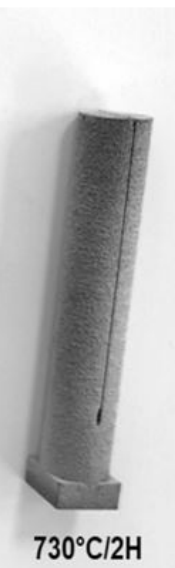

$730^{\circ} \mathrm{C} / 2 \mathrm{H}$

Figure 6 : Some of the samples that underwent various heat treatments. The variations of the deformation after EDM cutting is clearly visible.

All measurements of $[\mathrm{AB}]$ distance are performed on two samples and the results are reported in Figure 7 . This deformation is then converted to a stress relieving proportion. The $100 \%$ stress relieved $[\mathrm{AB}]$ value is calibrated on the as-built diameter [AB] of the samples before any EDM cutting. 


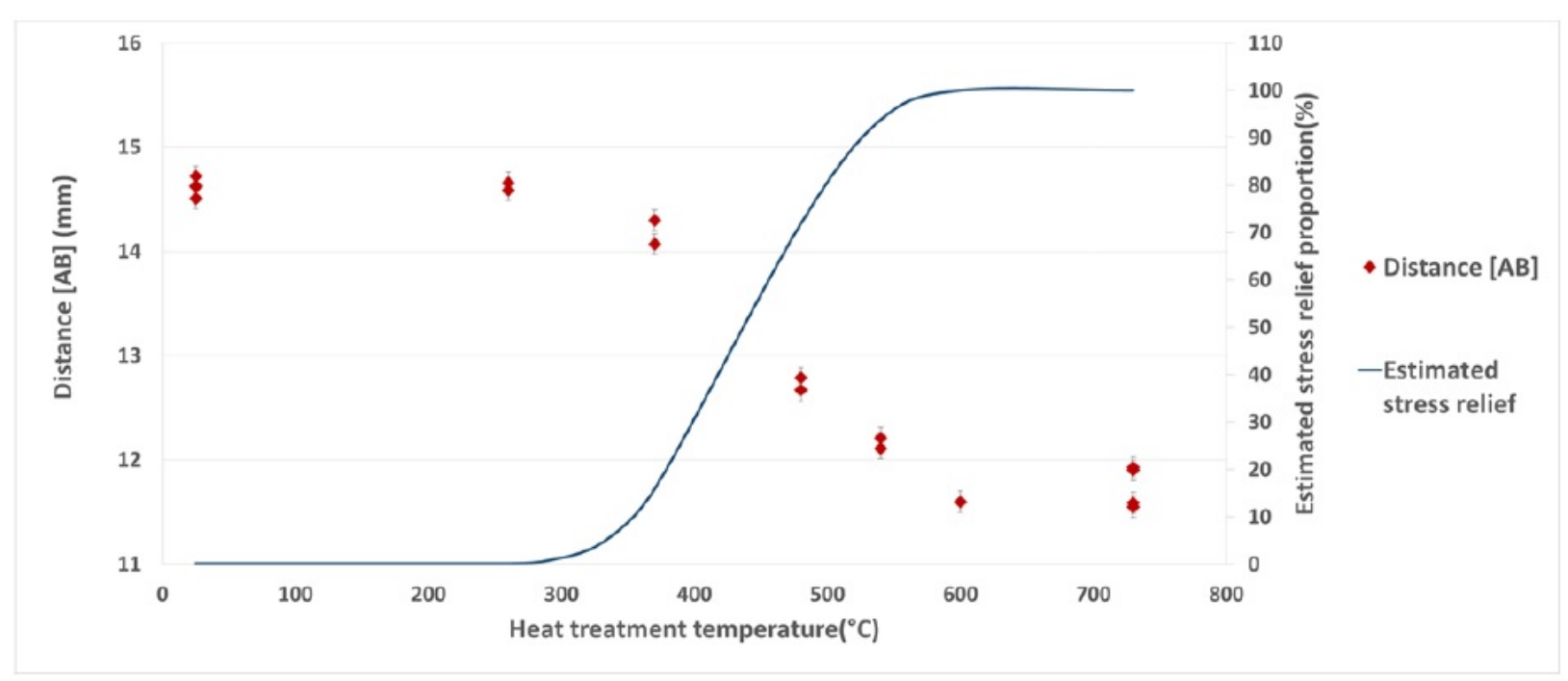

Figure 7 : Deformations measured on heat treated samples during 2 hours at different temperatures and the estimated proportion of the stress relief.

This diagram shows that for a two hours heat treatment, a temperature inferior to $370^{\circ} \mathrm{C}$ has almost no effect on the RS, but that above this temperature an important stress relief occurs. A minimum temperature of $600^{\circ} \mathrm{C}$ during two hours was found to be sufficient to suppress almost completely the RS.

Caution should be taken regarding the cooling time for heat treatments superior to $600^{\circ} \mathrm{C}$ as a difference in the [AB] distance was measured between air quenched and slowly cooled down samples after a $730^{\circ} \mathrm{C} / 2 \mathrm{H}$ heat treatment. For the air quenched samples, the distance [AB] is slightly superior. It is possible that the measurement technique is fine enough to detect RS generated by the cooling after the thermal stress relieving. More heat treatments with multiple cooling times will be performed in the future to evaluate this hypothesis.

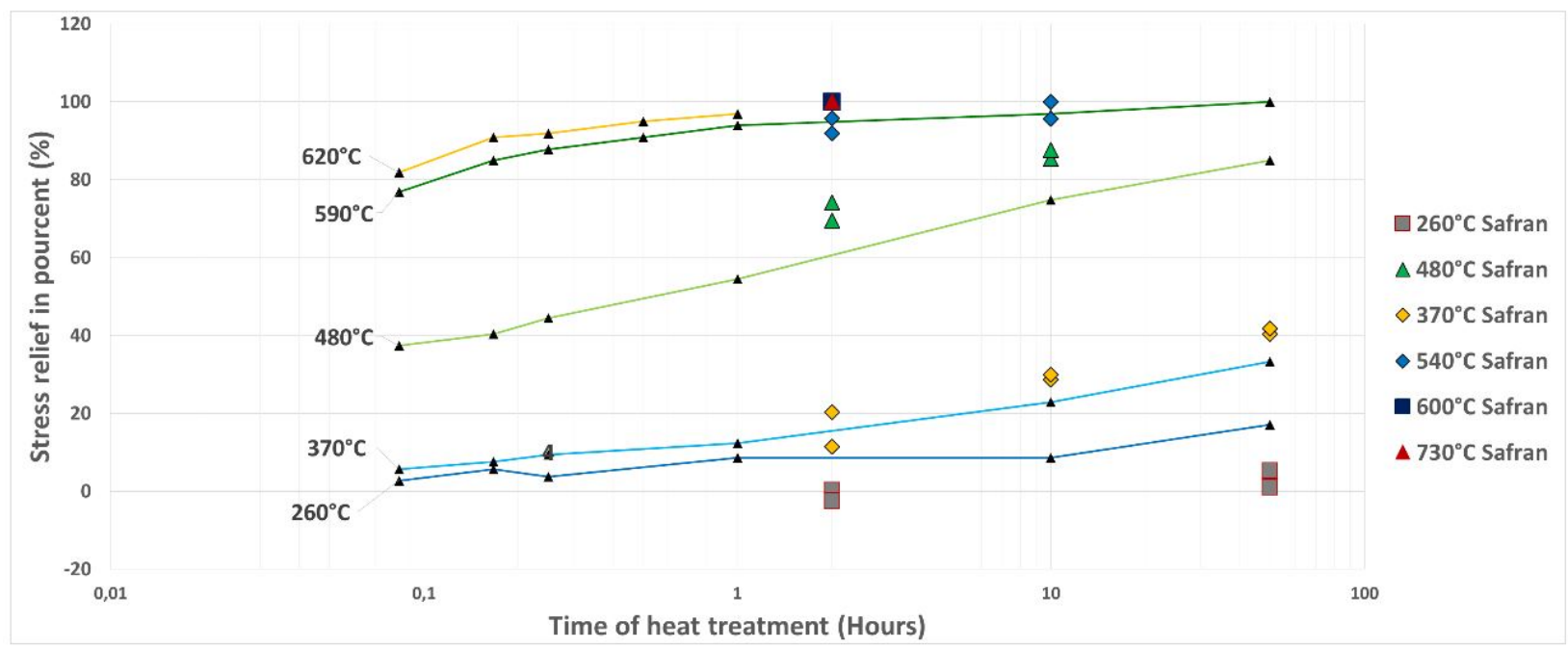

Figure 8 : Comparison between results from [12] and the estimated stress relief from this study at various heat treatment temperatures and soaking times.

The results showed a good correlation with previously published results for wrought Ti64 [12] as shown in Figure 8. It can be seen that stress relief increases with the temperature of the heat treatment, especially for temperatures superior to $370^{\circ} \mathrm{C}$. The influence of the soaking time on the stress relieving was also studied for low temperatures, ranging from $260^{\circ} \mathrm{C}$ to $480^{\circ} \mathrm{C}$. A longer soaking time decreases the RS, except for the heat treatment at $260^{\circ} \mathrm{C}$ which does not seem to influence the RS. Starting from $600^{\circ} \mathrm{C}$, a soaking time superior to $2 \mathrm{H}$ does not affect the stress relief as it is already close to a maximum. Compared to existing data, it can be noticed that the stress relief for the present study is lower for the $260^{\circ} \mathrm{C}$ heat treatment and slightly higher for all the other temperatures. Nevertheless, all results are globally in good agreement. Slight discrepancies may be explained by differences in experimental procedures which are not detailed for previous work.

It seems that the stress relieve has not been influenced by the particular microstructure obtained by additive manufacturing and that the stress relief mechanism is close to what can be found in a conventional microstructure and manufacturing process.

Finally, an additional X-ray diffraction analysis using the $\sin ^{2}(\psi)$ method [13] was performed on an "as-built" and on a heat treated sample $\left(730^{\circ} \mathrm{C} / 2 \mathrm{H}\right)$, both prior to the EDM cutting. This analysis confirmed the reduction of the residual stress from $810 \mathrm{MPa} \pm 105$ to $48 \mathrm{MPa} \pm 39 \mathrm{in}$ the $\mathrm{Z}$ direction of the samples. These results are consistent with the RS provided by Simufact that was comprised between $830 \mathrm{MPa}$ and $100 \mathrm{MPa}$.

\section{Microstructure}

The typical microstructure of Ti64 is composed of hexagonal close-packed (HCP) $\alpha$ phase and body-centred cubic (BCC) $\beta$ phase. Here, due to the very high cooling rate in the LBM process, this usual microstructure is replaced by a very fine martensitic hexagonal $\alpha$ 'structure. The microstructure was observed after three different heat treatments.

The as-built microstructure as seen in Figure 9 is mostly composed of acicular $\alpha$ 'needles. On the optical micrographs the prior epitaxial $\beta$ grains and the building layers are still clearly visible after etching.

At $480^{\circ} \mathrm{C}$, the initial martensite should decompose into $\alpha+\beta$ lamellae. This transformation was not clearly visible here. As previously reported in [14], the microstructure changed only slightly when compared with the as-built material. The width and features modifications of the lamellae are not significant. 
After $2 \mathrm{H}$ at $730^{\circ} \mathrm{C}$, there is no significant change in the grain morphology. Only a slight thickening of the needles was observed and also the formation of $\alpha+\beta$ particles between the $\alpha$ ' laths as reported in [15].

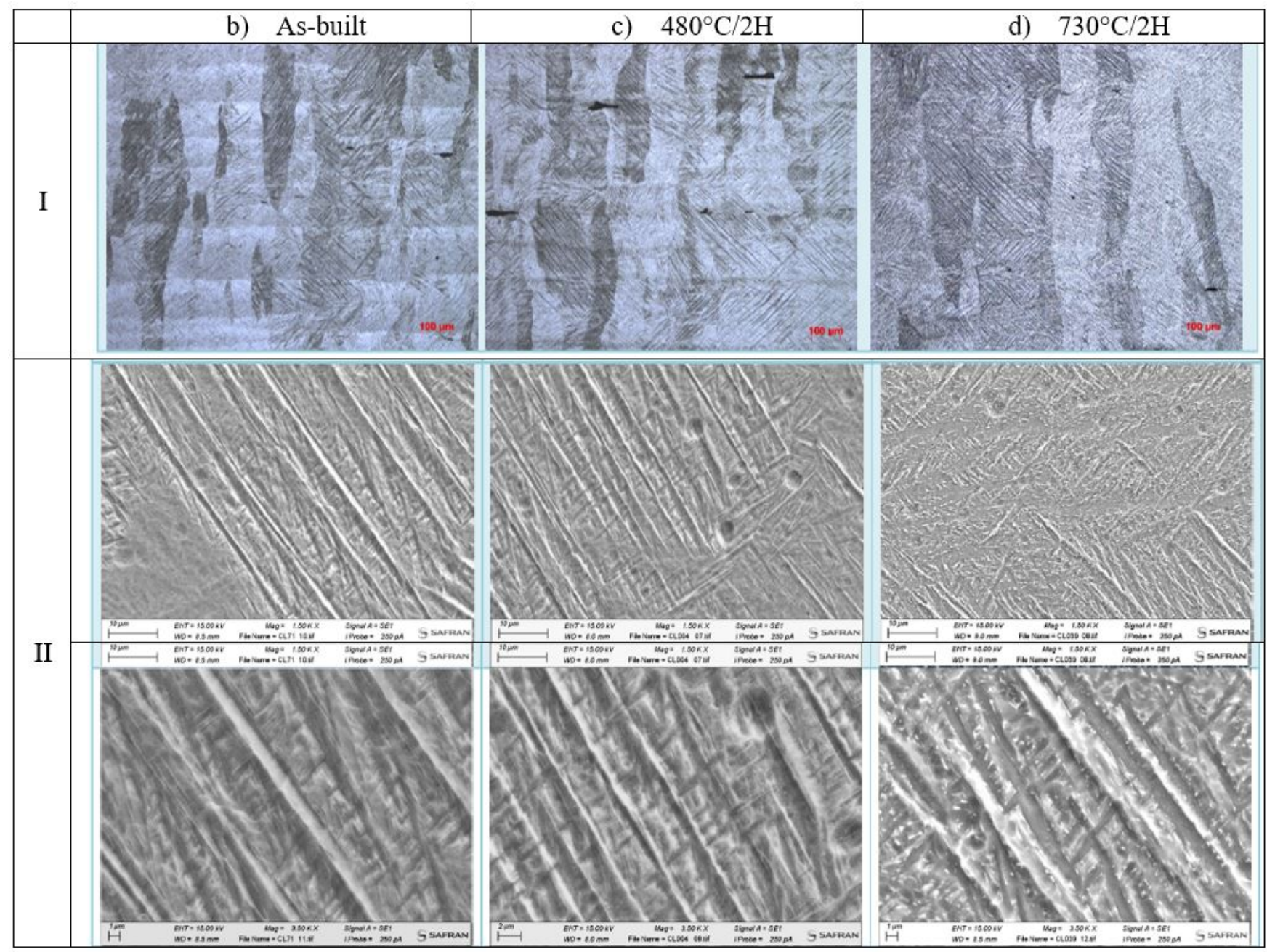

Figure 9 : Different optical micrographs (I) and SEM images (II) for different heat tretment, respectivly (a) "as-built", (b) $480^{\circ} \mathrm{C} / 2 \mathrm{H} \mathrm{and} \mathrm{(c)} 730^{\circ} \mathrm{C} / 2 \mathrm{H}$.

Those analyses confirm the fact that at such temperatures, those treatments can only be reported as stress relief heat treatments as they do not drastically change the microstructure, even for the metastable state coming from the LBM process.

\section{$\underline{\text { Conclusion }}$}

The simple and yet effective method developed here, has been successfully used to compare different parameters of thermal stress relief. The data obtained allowed us to compare the behaviour of additively manufactured parts and conventional ones, showing that a temperature of $600^{\circ} \mathrm{C}$ during two hours could be sufficient to relieve the residual stress from parts build with the LBM process. This technique could also be used to test and compare additive manufacturing processes, LBM machine models, simulation software, materials, parameters, and stress relieving operations.

\section{$\underline{\text { References }}$}

[1] J. L. Bartlett and X. Li, “An overview of residual stresses in metal powder bed fusion,” Additive Manufacturing, vol. 27. Elsevier B.V., pp. 131-149, 01-May-2019.

[2] C. Li, Z. Y. Liu, X. Y. Fang, and Y. B. Guo, "Residual Stress in Metal Additive Manufacturing,” in Procedia CIRP, 2018, vol. 71, pp. 348-353.

[3] L. Parry, I. A. Ashcroft, and R. D. Wildman, "Understanding the effect of laser scan strategy on residual stress in selective laser melting through thermo-mechanical simulation," Addit. Manuf., vol. 12, pp. 1-15, Oct. 2016.

[4] J. Buchbinder, D., Meiners, W., Pirch, N., Wissenbach, K., \& Schrage, "Investigation on reducing distortion by preheating during manufacture of aluminum components using selective laser melting.," J. Laser Appl., no. 012004., p. 26(1), 2014.

[5] M. Strantza et al., "Coupled experimental and computational study of residual stresses in additively manufactured Ti-6Al-4V components," Mater. Lett., vol. 231, pp. 221-224, Nov. 2018.

[6] R. J. Williams, P. A. Hooper, and C. M. Davies, "Finite element prediction and validation of residual stress profiles in 316L samples manufactured by laser powder bed fusion,” Procedia Struct. Integr., vol. 13, pp. 1353-1358, Dec. 2018.

[7] J. Robinson, I. Ashton, P. Fox, E. Jones, and C. Sutcliffe, "Determination of the effect of scan strategy on residual stress in laser powder bed fusion additive manufacturing," Addit. Manuf., vol. 23, pp. 13-24, Oct. 2018. 
[8] B. Ahmad, S. O. van der Veen, M. E. Fitzpatrick, and H. Guo, "Residual stress evaluation in selective-laser-melting additively manufactured titanium (Ti-6Al-4V) and inconel 718 using the contour method and numerical simulation," Addit. Manuf., vol. 22, pp. 571-582, Aug. 2018.

[9] M. Siewert, F. Neugebauer, J. Epp, and V. Ploshikhin, "Validation of Mechanical Layer Equivalent Method for simulation of residual stresses in additive manufactured components," Computers and Mathematics with Applications, Elsevier Ltd, 2018.

[10] E. W. (Eds. . Welsch, G., Boyer, R., \& Collings, Materials properties handbook: titanium alloys. 1993.

[11] B. C. Y.Combres, "Traitements thermiques des alliages de titane," Tech. l'ingénieur, 1991.

[12] R. A. W. F.F.Schmidt, "Heat Treatment of titanium alloys," 1966.

[13] V. (Ed. ). Hauk, Structural and residual stress analysis by nondestructive methods: Evaluation-Application-Assessment. 1997.

[14] X. Y. Zhang, G. Fang, S. Leeflang, A. J. Böttger, A. A. Zadpoor, and J. Zhou, "Effect of subtransus heat treatment on the microstructure and mechanical properties of additively manufactured Ti-6Al-4V alloy,” J. Alloys Compd., vol. 735, pp. 1562-1575, Feb. 2018.

[15] H. Ali, L. Ma, H. Ghadbeigi, and K. Mumtaz, "In-situ residual stress reduction, martensitic decomposition and mechanical properties enhancement through high temperature powder bed pre-heating of Selective Laser Melted Ti6Al4V," Mater. Sci. Eng. A, vol. 695, pp. 211-220, May 2017. 